\title{
Design of PLC-based electro hydraulic servo position closed loop system
}

\author{
Jian Xue ${ }^{1, a}$, Mingyuan $\mathrm{Lu}^{2}$ \\ ${ }^{1}$ Department of Information Engineering, Hefei University of Technology, Xuancheng 242000, \\ China \\ ${ }^{2}$ School of Mechanical and Vehicle Engineering, Changzhou Institute of Technology, Changzhou \\ 213000, China \\ a1982132366@qq.com
}

Keywords: PLC; electro hydraulic servo; PID closed loop control; position control

Abstract. The electro-hydraulic servo position closed-loop system is a high-precision control system with wide application, we established a mathematical model of hydraulic servo closed-loop system at first to design SIEMENS S7-1500 PLC-based electro-hydraulic servo position closed-loop control system, and to achieve high-precision position closed-loop control by adopting PID control algorithm.

\section{Introduction}

Due to high pressure and precise position control, the electro-hydraulic servo control system has been increasingly widely applied in industrial sector. Along with the development of servo control technology [1], using PLC as the control core to build a servo control system featuring simple and easy maintenance and high extendability has gradually become the trend. SIEMENS's new CPU S7-1500 series high-end CPU 1517-3 has 2ns bit logic operation speed, fully suitable for the production of high-precision electro-hydraulic servo system. We adopted CPU 1517-3 as control template to carry on experimental study in electro-hydraulic servo system experimental platform, and advanced language to perform loop algorithm programming, the results indicating that PLC -based high precision electro-hydraulic servo control system was of great practical significance.

\section{System scheme}

The stretching position of piston rod of piston-type hydraulic cylinder was controlled by regulating the servo valve current of hydraulic servo system, and a magnetostrictive displacement sensor with the detection accuracy of $1 \pm 1$ um was installed in the inside of piston-type hydraulic cylinder with SSI digital signals as output signal. The servo valve was controlled by comparing the displacement collected by PLC and given displacement, and closed-loop control algorithm was adopted based on deviation in PLC, to finally achieve micron-level hydraulic cylinder position closed-loop control, the principle diagram is as shown in figure 1:

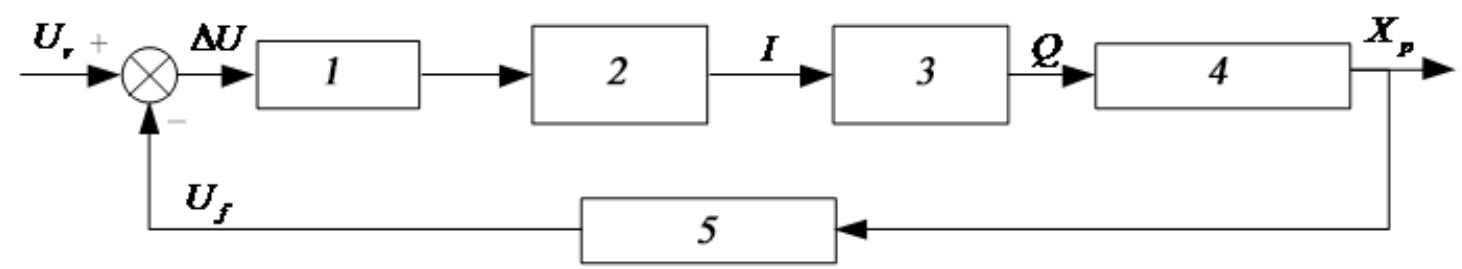

1.Controller;2.Servo amplifier;3.Electro hydraulic servo valve;4.Hydraulic cylinder;5.Displacement transducer Fig. 1 Schematic diagram of electro hydraulic servo closed loop system

\section{Mathematical model of position closed loop control system}

In addition to controller, position closed-loop system is composed of servo hydraulic cylinder, servo valve, displacement sensor and servo amplifier. Bringing transfer functions of each element 
into the block diagram shown in Figure 1, to derive a mathematical model of position closed-loop system as shown in Figure 2 [2], and a simplified one in Figure 3:

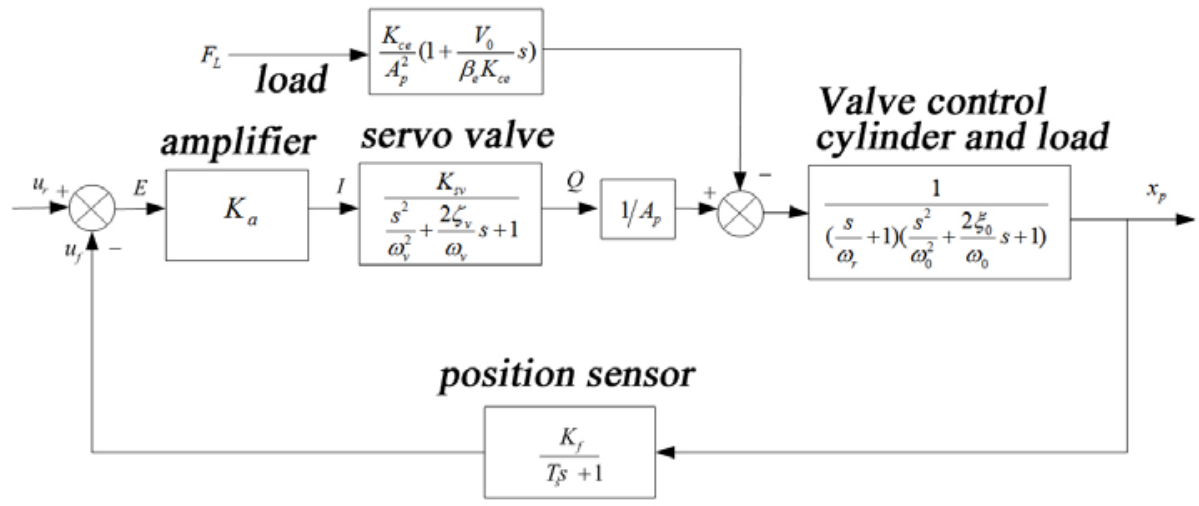

Fig. 2 Block diagram of position closed loop system model

In figure 2, $K_{a}$ _ Servo amplifier gain ( $\left.\mathrm{A} / \mathrm{V}\right)$;

$K_{f} \_$Sensor gain $(\mathrm{V} / \mathrm{m})$;

$\xi_{0}$ _Comprehensive damping ratio, $\xi_{0}=\frac{1}{2 \omega_{0}}\left(\frac{\beta_{e} K_{c e}}{V_{0}\left(1+K_{S} / K_{h}\right)}+\frac{B_{p}}{m_{t}}\right)$ 。

$A_{p} \_$Effective area of piston of hydraulic cylinder $\left(\mathrm{m}^{2}\right)$;

$K_{s v} \_$Servo valve flow gain $\left(\left(\mathrm{m}^{3} / \mathrm{s}\right) / \mathrm{A}\right)$;

$\omega_{0}$ _comprehensive natural frequency $(\mathrm{rad} / \mathrm{s}), \quad \omega_{0}=\sqrt{\omega_{h}{ }^{2}+\omega_{m}{ }^{2}}=\omega_{h} \sqrt{1+\frac{K_{S}}{K_{h}}}$;

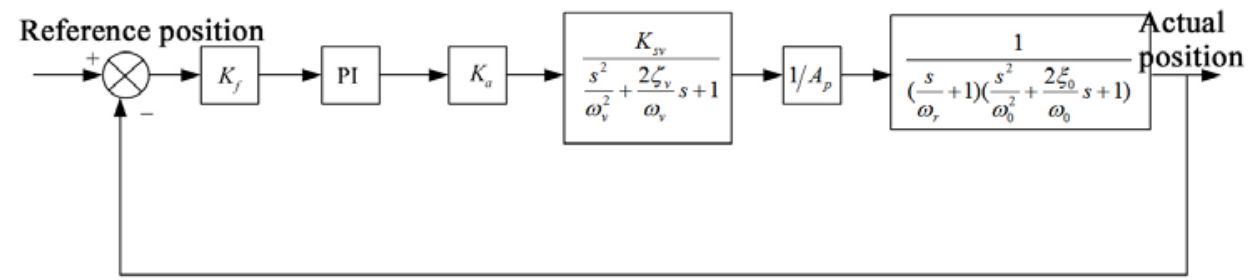

Fig. 3 Simplified block diagram of position closed loop system model

Based on the model block diagram shown in Figure 3, the open loop model of the system is as follows:

$$
G(s)=\frac{\left(K_{f} \times K_{a} \times K_{s v}\right) / A_{p}}{\left(\frac{s^{2}}{\omega_{v}^{2}}+\frac{2 \xi_{v}}{\omega_{v}} s+1\right)\left(\frac{s}{\omega_{r}}+1\right)\left(\frac{s^{2}}{\omega_{0}^{2}}+\frac{2 \xi_{0}}{\omega_{0}} s+1\right)}
$$

Based on formula 1, the mathematical model of the system is a 6-order complex system. As servo valve and sensor had rapid response, small factors were ignored when simplifying mathematical model, and a simplified mathematical model was derived as follows:

$$
G(s)=\frac{\left(K_{d} \times K_{a} \times K_{s v}\right) / A}{s\left(\frac{s^{2}}{\omega_{0}^{2}}+\frac{2 \xi_{0}}{\omega_{0}} s+1\right)}
$$

In the experiment system, approximate values of key parameters shown in Table 1 were brought in formula 2 to derive final approximate simplified mathematical model as follows:

$$
G(s)=\frac{0.33}{3.601 \times 10^{-6} s^{3}+0.002657 s^{2}+s}
$$


Table 1 Approximate values of key parameters

\begin{tabular}{llllll}
\hline$K_{a}(\mathrm{~V} / \mathrm{A})$ & $K_{d}(\mathrm{~V} / \mathrm{m})$ & $\xi_{0}$ & $A\left(\mathrm{~m}^{2}\right)$ & $K_{\mathrm{sv}}\left(\left(\mathrm{m}^{3} \cdot \mathrm{s}\right) / \mathrm{A}\right.$ & $\omega_{0}(\mathrm{rad} / \mathrm{s})$ \\
\hline 0.001 & 14500 & 0.89 & 0.4985 & 0.3161 & 0.7 \\
\hline
\end{tabular}

\section{Design of PLC control system}

The experimental system consisted of PLC as the control core, SIEMENS's new S7-1500 series module and CPU1517-3DP/PN template. In addition to the conventional digital input and output, high speed AO templates were used as the output of servo valve, and special process template TM PosInput 2 module was adopted to collect SSI displacement signal [4-5], the hardware list of PLC is as shown in table 2.

Table 2 Hardware list of PLC

\begin{tabular}{l|l|l}
\hline Name & Serial number & $\begin{array}{l}\text { quantit } \\
\mathrm{y}\end{array}$ \\
\hline Guideway S7-1500, 160mm & $\begin{array}{l}\text { 6SE7590-1AB60-0 } \\
\text { AA0 }\end{array}$ & 1 \\
\hline $\begin{array}{l}\text { System power supply PS25W } \\
\text { 24VDC }\end{array}$ & $\begin{array}{l}\text { GSE7505-0KA00-0 } \\
\text { AB0 }\end{array}$ & 1 \\
\hline CPU 1517-3PN.DP & $\begin{array}{l}\text { 6ES751-73AP00-0 } \\
\text { AB0 }\end{array}$ & 1 \\
\hline Digital input DI32*24VDC HF & $\begin{array}{l}\text { 6SE7521-1BL00-0 } \\
\text { AB0 }\end{array}$ & 1 \\
\hline $\begin{array}{l}\text { Digital output DQ32*24VDC/0.5A } \\
\text { ST }\end{array}$ & $\begin{array}{l}\text { 6SE7522-1BL00-0 } \\
\text { AB0 }\end{array}$ & 1 \\
\hline Analog input AI8*U/IRTD/TC ST & $\begin{array}{l}\text { 6SE7531-7KF00-0 } \\
\text { AB0 }\end{array}$ & 1 \\
\hline Analog output AQ8*U/I HS & $\begin{array}{l}\text { 6SE7532-5HF00-0 } \\
\text { AB0 }\end{array}$ & 1 \\
\hline Process module TM PosInput 2 & $\begin{array}{l}\text { 6SE7551-1AB00-0 } \\
\text { AB0 }\end{array}$ & 1 \\
\hline Memory card 24MB & $\begin{array}{l}\text { 6SE7954-8LF02-0 } \\
\text { AA0 }\end{array}$ & 1 \\
\hline $\begin{array}{l}\text { Front end connector, screw } \\
\text { terminal, 40 pin }\end{array}$ & $\begin{array}{l}\text { 6SE7592-1AM00-0 } \\
\text { XB0 }\end{array}$ & 5 \\
\hline
\end{tabular}

The principle of PID control algorithm applied in position closed loop control system is shown below:

$$
u(k)=K_{P} e(k)+K_{I} \sum_{j=0}^{k} e(j)+K_{D}(e(k)-e(k-1))
$$

Integrated PID closed-loop configuration panel was used in TIA Portal software to construct a closed loop programming as shown in Figure 4. 


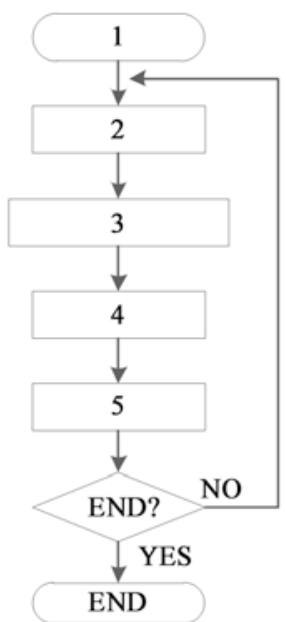

1.Initialization;2.Set target position;3.Detecting the actual position of the servo oil cylinder;4.PID closed loop control;5.Electro hydraulic servo valve

Fig. 4 Position closed loop control flow

Ideal control effect can be achieved by adjusting the parameters of the closed loop program such as $K_{P}, K_{I}$ and $K_{D}$.

\section{Verification of control effect}

First of all, an experimental platform was set up, and then hardware was connected and software program was written to verify the control precision of closed loop system. The S7-TREND data acquisition software was applied to perform online data collection to the internal address of S7-1500 register, and figure 5 shows the process response curve after several times of adjustment of PID parameters.

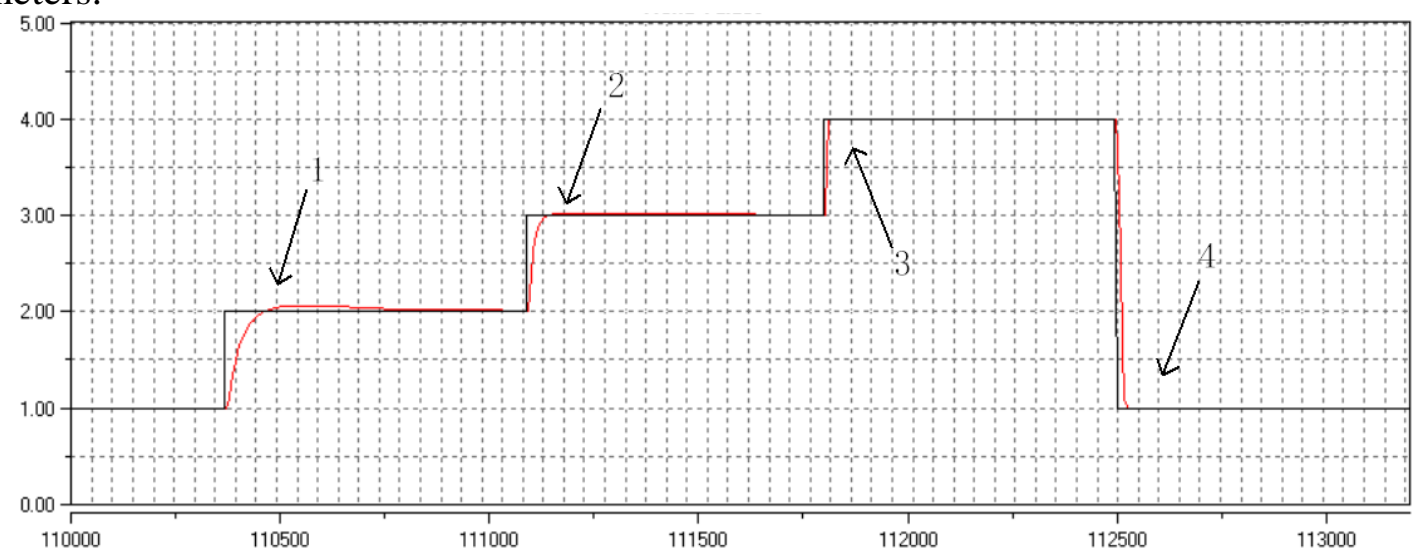

Fig. 5 PID control response curve of position closed loop

Curve 1 is the one when $K_{P}=0.4, K_{I}=0.3 \mathrm{~m}$ and $K_{D=0 \mathrm{~min}}$ which were predicted based on mathematical model with step response as $1 \mathrm{~mm}$. As system steady-state error and rise time changed slowly, $K_{P}$ was increased to 2.4 to obtain determination effect of curve 2 based on parameter debugging experience of PID controller, and rise time improved slightly, but the control precision was still low. After many times of adjustments, PID parameters were determined as $K_{P}=5.8$,

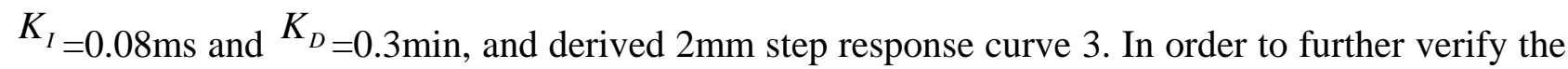
effect of step response with larger amplitude, negative (servo cylinder retraction direction) 4mm step was given to obtain results are shown in response curve 4. It can be learnt from curve 3 and 4 that high closed-loop response accuracy was obtained after several times of adjustment of PID parameters, verifying the feasibility of PLC-based electro hydraulic servo position closed-loop control system. 


\section{Conclusion}

Through the research on electro-hydraulic servo position closed-loop system, we designed PLC-based position closed-loop system. First of all, we fully understood the principle of position closed-loop through mathematical modeling of position closed-loop system, and verified the position closed-loop effects of servo system by building PID control software on PLC, to finally realize ideal control accuracy by adjusting PID parameters, so as to verify the high application of PLC in high precision closed-loop electro-hydraulic servo system.

\section{Reference}

[1]. Mao Linmeng, Pu Xinrong and Han Qing et al., Design of PLC Position Closed-Loop of Electro-Hydraulic Servo System Control System [J]. Equipment Manufacturing Technology, 2014 (10): 92-94.

[2]. Wei Lixin, Zheng Cuihong and Wang Hongqing et al. Experimental Study on RBF Neural Network in Cold Rolling APC System [J]. Mechanical Design and Manufacturing, 2014 (9): 159-163.

[3]. Mao Linmeng, Pu Xinrong and Han Qing et al., Design of PLC Position Closed-Loop of Electro-Hydraulic Servo System Control System [J]. Equipment Manufacturing Technology, 2014 (10): 92-94.

[4]. Li Yanjie, Cui Tianyu and Wang Hai et al. Proportional Valve Controlled Hydraulic Cylinder PID Closed Loop PLC Software [J]. PID Journal of ShenYang Ligong University, 2013, 32 (4): 37-40.

[5]. Liang Jun and Wang Yichuan. Design of SSI Interface Based Line Displacement Sensor High Speed Parallel Data Acquisition [J]. Measurement and Control Technology, 2012, 31 (5): 53-54. 